\title{
Article
}

\section{A rich gallery of carbon dots based photoluminescent suspensions and powders derived by citric acid/urea}

Stachowska, Joanna, Murphy, Andrew, Mellor, Claire, Fernandes, Diogo, Gibbons, Ella Nicole, Krysmann, Marta, Kelarakis, Antonios, Burgaz, Engin, Moore, Joshua and Yeates, Stephen G.

Available at http://clok.uclan.ac.uk/37872/

Stachowska, Joanna, Murphy, Andrew, Mellor, Claire ORCID: 0000-0002-76472085, Fernandes, Diogo, Gibbons, Ella Nicole ORCID: 0000-0003-4931-2681, Krysmann, Marta ORCID: 0000-0002-8036-4925, Kelarakis, Antonios ORCID: 0000-0002-8112-5176, Burgaz, Engin, Moore, Joshua et al (2021) A rich gallery of carbon dots based photoluminescent suspensions and powders derived by citric acid/urea. Scientific Reports, 11 (1). p. 10554.

It is advisable to refer to the publisher's version if you intend to cite from the work. http://dx.doi.org/10.1038/s41598-021-89984-w

For more information about UCLan's research in this area go to http://www.uclan.ac.uk/researchgroups/ and search for <name of research Group>.

For information about Research generally at UCLan please go to http://www.uclan.ac.uk/research/

All outputs in CLoK are protected by Intellectual Property Rights law, including Copyright law. Copyright, IPR and Moral Rights for the works on this site are retained by the individual authors and/or other copyright owners. Terms and conditions for use of this material are defined in the policies page. 


\title{
scientific reports
}

Check for updates

\section{OPEN A rich gallery of carbon dots based photoluminescent suspensions and powders derived by citric acid/} urea

\begin{abstract}
Joanna D. Stachowska ${ }^{1}$, Andrew Murphy ${ }^{2}$, Claire Mellor ${ }^{3}$, Diogo Fernandes ${ }^{4}$, Ella N. Gibbons ${ }^{1}$, Marta J. Krysmann ${ }^{2}$, Antonios Kelarakis ${ }^{2 凶}$, Engin Burgaz ${ }^{5}$, Joshua Moore ${ }^{6}$ \& Stephen G. Yeates ${ }^{6}$

In this study we demonstrate simple guidelines to generate a diverse range of fluorescent materials in both liquid and solid state by focusing on the most popular C-dots precursors, i.e. the binary systems of citric acid and urea. The pyrolytic treatment of those precursors combined with standard size separation techniques (dialysis and filtration), leads to four distinct families of photoluminescent materials in which the emissive signal predominantly arises from C-dots with embedded fluorophores, cyanuric acid-rich C-dots, a blend of molecular fluorophores and a mixture of C-dots with unbound molecular fluorophores, respectively. Within each one of those families the chemical composition and the optical properties of their members can be fine-tuned by adjusting the molar ratio of the reactants. Apart from generating a variety of aqueous dispersions, our approach leads to highly fluorescent powders derived from precursors comprising excessive amounts of urea that is consumed for the build-up of the carbogenic cores, the molecular fluorophores and the solid diluent matrix that suppresses self-quenching effects.
\end{abstract}

A distinct advantage of carbogenic nanoparticles (refereed hereafter as C-dots) is their scalable and low cost synthesis by means of pyrolytic treatment of virtually any type of carbon-rich material, including abundant and renewable resources ${ }^{1}$ such as biomass ${ }^{2}$, grass ${ }^{3}$, leaves ${ }^{4}$, fruits ${ }^{5}$, eggs ${ }^{6}$ or even bacteria ${ }^{7}$. Despite the simplicity and the template-free nature of those bottom-up synthetic approaches, they lead to well-defined C-dots whose structural and morphological characteristics largely depend on the nature of the precursor materials and the synthesis conditions (temperature, time, dispersion medium, etc.) ${ }^{8-11}$. Typically, the radius of pyrolytically derived C-dots falls within 2-20 nm, although nanospheres with size in excess of $50 \mathrm{~nm}$ have also been demonstrated ${ }^{12,13}$.

In addition to their preparation ease, $\mathrm{C}$-dots exhibit supreme photoluminescent (PL) properties and show low toxicity for humans and the environment ${ }^{14}$. Owning to this unique combination of desired characteristics, C-dots are systematically explored for the development of photocatalysts ${ }^{15}$, photovoltaics ${ }^{16}$, light emitting diodes ${ }^{17}$, chemical nanosensors ${ }^{18}$, bio-imaging agents ${ }^{19}$, cancer therapy vehicles ${ }^{20}$ and polymer nanocomposites ${ }^{21,22}$. In contrast to the large number of studies centred around their aqueous dispersions, only few reports focus on C-dots nano-powders ${ }^{23,24}$, a nevertheless very interesting class of materials that is prone to self-quenching ${ }^{25}$.

In principle, pyrolytically derived C-dots exhibit excitation wavelength $\left(\lambda_{\mathrm{ex}}\right)$ dependent PL emission with quantum yields (QY) in the range of $2-15 \%^{2}$, while C-dots with improved emission efficiency have also been shown $^{7,26}$. As a general trend, the QY can be substantially improved via heteroatom doping, surface functionalization and passivation ${ }^{8-10}$, while application of a voltammetric field might have a profound impact to the PL intensity ${ }^{27}$. It has been well-established that molecular fluorophores are often coproduced during the synthesis of C-dots ${ }^{28-30}$ and their presence has a profound impact on the optical properties of the resulting material.

In this work we focus on the pyrolytic treatment of citric acid (CA)/urea mixtures (with various molar ratios) that remain the most popular precursor systems for the synthesis of C-dots, an approach that unavoidably

\footnotetext{
${ }^{1}$ School of Pharmacy and Biomedical Sciences, University of Central Lancashire, Preston PR12HE, UK. ${ }^{2}$ UCLan Research Centre for Smart Materials, School of Natural Sciences, Preston PR12HE, UK. ${ }^{3}$ School of Psychology, University of Central Lancashire, Preston PR12HE, UK. ${ }^{4}$ Malvern Panalytical, Enigma Business Park, Grovewood Road, Malvern WR14 1XZ, UK. ${ }^{5}$ Faculty of Engineering, Department of Metallurgical and Materials Engineering, Ondokuz Mayis University, 55139 Atakum, Samsun, Turkey. ${ }^{6}$ School of Chemistry, University of Manchester, Manchester M13 9PL, UK. ${ }^{\circledR}$ email: akelarakis@uclan.ac.uk
} 


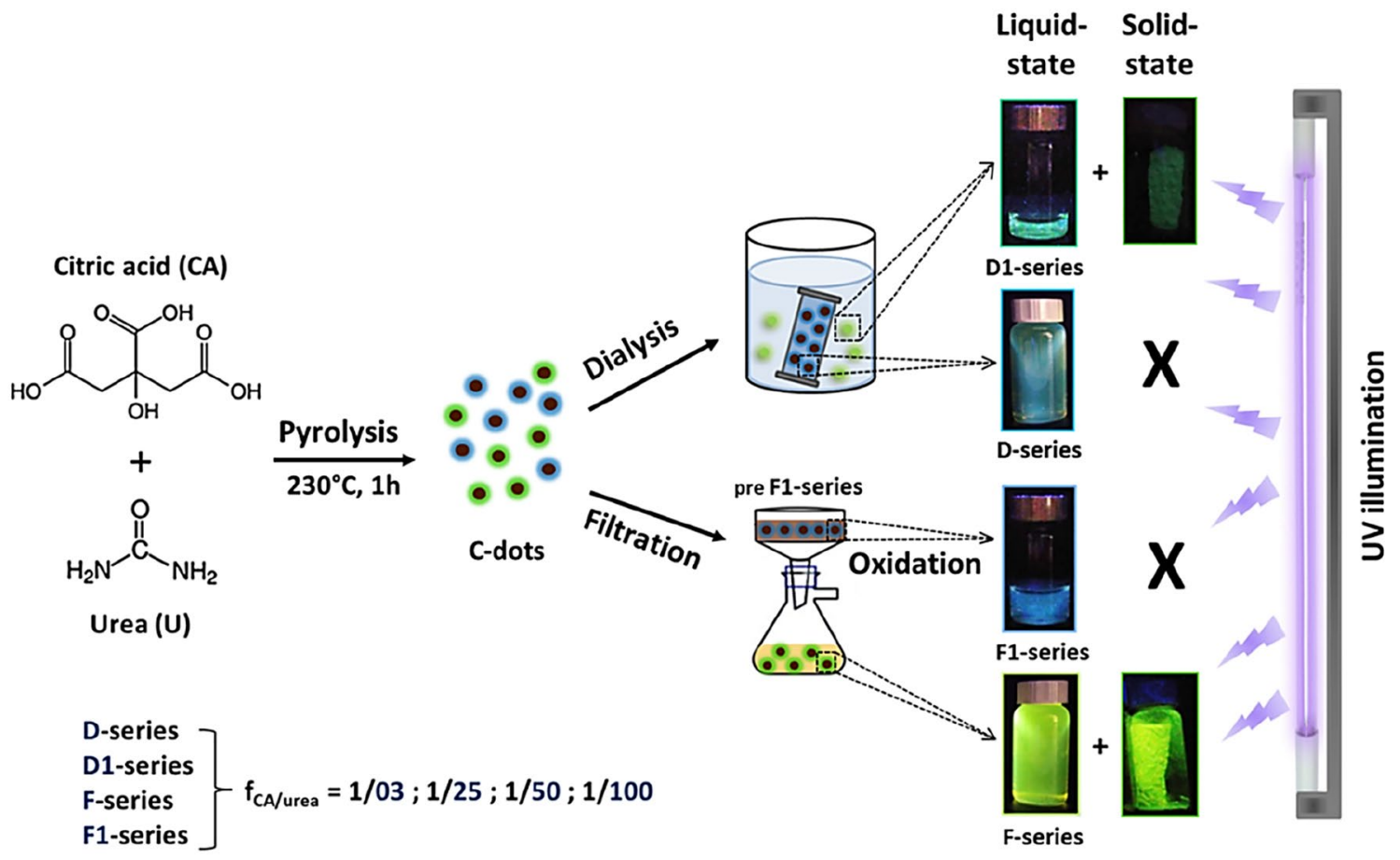

Figure 1. Schematic representation of the synthetic and purification approach followed for the preparation of four series of photoluminescent liquids and solids, all derived by means of pyrolytic treatment of CA and urea precursor mixtures.

proceeds with the parallel formation of molecular fluorophores. We note that a similar approach can be followed using a variety of binary combinations of precursor materials such as urea/malic acid ${ }^{31}$, urea/glycolic acid $^{31}$, urea/sodium citrate ${ }^{32}$, urea/potassium citrate ${ }^{32}$, ethanolamine/CA ${ }^{28}$, (hydroxymethyl)aminomethane/ $\mathrm{CA}^{33}$, dicyandiamide/ $\mathrm{CA}^{34}$, etc.

Figure 1 outlines the synthetic and purification strategies followed to produce a family of extensively dialysed C-dots (D-series) and the corresponding run-off substances (D1-series). Alternatively, the carbonaceous pyrolysis products were subjected to filtration to generate a family of hybrid materials comprising both nanoparticles and unbound molecular fluorophores (F-series), while the solid residues (preF1-series) were oxidised via $\mathrm{HNO}_{3}$ resulting in yet another photoactive type of materials (F1-series).

Within the extensive body of literature centred around the use of CA/urea mixtures as C-dot precursors, the present work distinguishes itself and contributes novel insights in three directions. First, the report further highlights the versatility of the pyrolytic approaches used for the synthesis of C-dots and the rich diversity of the materials produced thereby, via the preparation and characterization of a large gallery of CA/urea derived PL materials. Second, the study allows a direct and meaningful comparison between the D and F series, thus facilitating a quantitative assessment of the effect of molecular fluorophores on the optical properties of C-dots based dispersions. Third, the study discloses effective strategies to generate PL powders by employing excessive amounts of urea to serve simultaneously as the reactant for the synthesis of the molecular fluorophores, the carbon and nitrogen source for the build-up of the carbogenic cores, and as the diluent matrix that suppresses undesired self-quenching effects.

\section{Results and discussion}

Characterization. D-series. The Scanning Transmission Electron Microscopy (STEM) images displayed in Fig. 2a-d indicate the spherical nature of CU03D, CU25D, CU50D and CU100D nanoparticles, with mean diameters 14, 16.1, 17.6 and $13.7 \mathrm{~nm}$, respectively (data derived via statistical analysis with $\mathrm{N}=200-600$ as shown in Fig. S1). Previous studies suggested that the size of C-dots derived from CA/urea mixtures varies from 2 to $16 \mathrm{~nm}^{31,35,36,36-45}$. High Resolution Transmission Electron Microscopy (HRTEM) images of CU03D and CU50D (Fig. 2e, f) show lattice spacing close to $0.22 \mathrm{~nm}$ that is consistent with (100) facet of graphite. The X-ray diffraction (XRD) patterns of the four members of $\mathrm{D}$-series (Fig. $2 \mathrm{~g}$ ) are dominated by a sharp peak centred at $2 \theta=27.6^{\circ}$, in agreement with earlier reports on CA and CA/urea derived C-dots ${ }^{46-48}$. This diffraction peak is close to the (002) lattice spacing of graphite-type materials, further confirming the crystalline nature of the carbogenic core. Elemental analysis (Supplementary Information, Table S1) indicates that the nitrogen content for CU03D, CU25D, CU50D and CU100D, is $21 \%, 25 \%, 28 \%$ and 33\%, respectively and this trend is accompanied by a systematic decrease in the carbon content from $47 \%$ for CU03D to $40 \%$ for CU100D. At the same time, all members of D-series maintain oxygen content between 24 to $28 \%$ and hydrogen content between 3 to $4 \%$. As expected, lower molar ratios of CA to urea $\left(\mathrm{f}_{\mathrm{CA} / \text { urea }}\right)$ lead to C-dots with enhanced nitrogen content ${ }^{40,49,50}$. For reference it is noted that solvothermal treatment $\left(5 \mathrm{~h}, 180^{\circ} \mathrm{C}\right)$ of a mixture with $\mathrm{f}_{\mathrm{CA} / \text { urea }}=1: 3$ results in $\mathrm{C}$-dots 

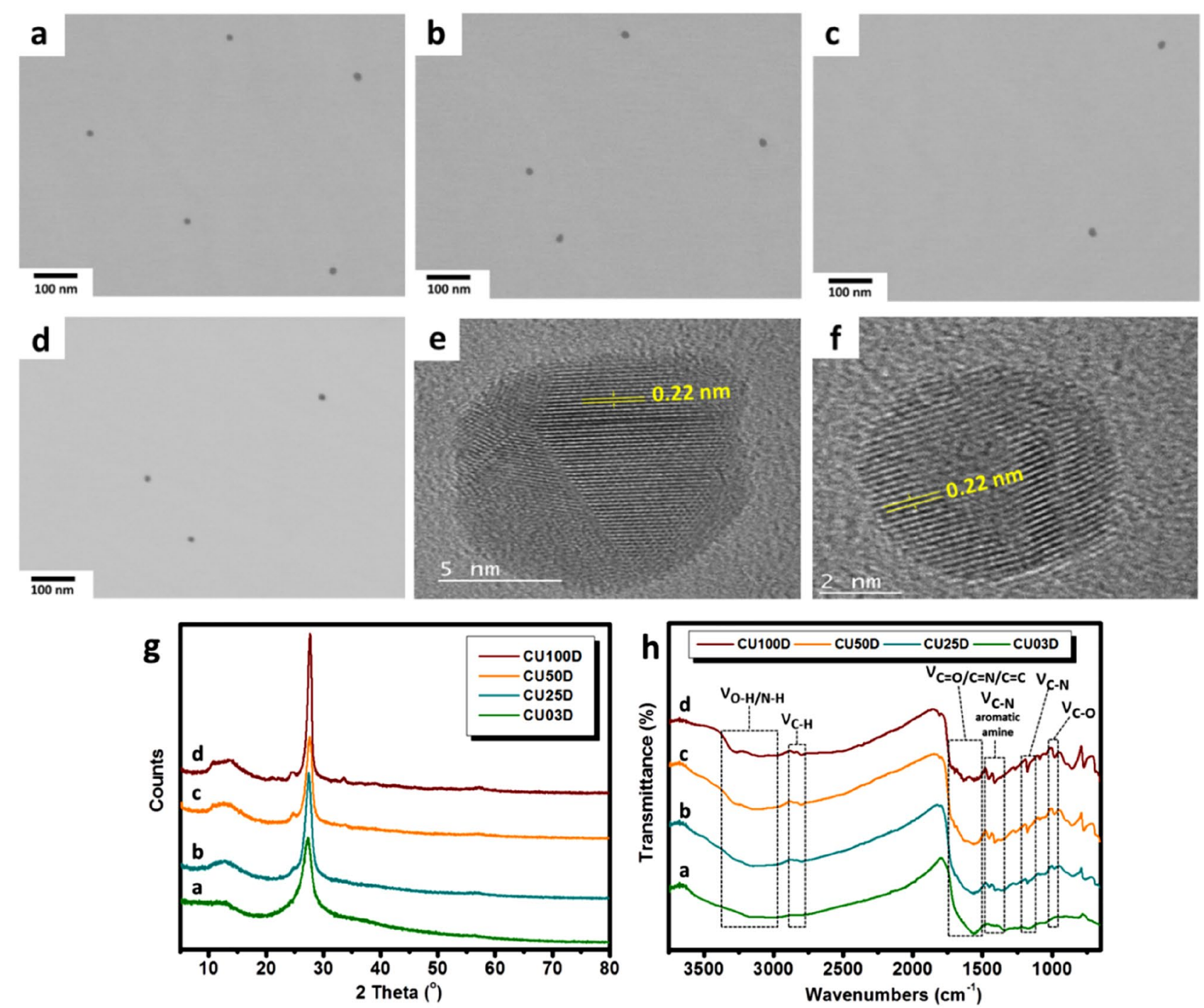

Figure 2. STEM images of CU03D (a), CU25D (b), CU50D (c) CU100D (d). HRTEM images of CU03D (e) and CU50D (f) XRD patterns (g) and FTIR spectra (h) of D-series.

containing $39.7 \%$ carbon, $23.2 \%$ nitrogen, and $32.3 \%$ oxygen $^{51}$, while a modified treatment $\left(6 \mathrm{~h}, 200{ }^{\circ} \mathrm{C}\right)$ of an identical precursor results in C-dots with $45.5 \%$ carbon, $31.7 \%$ nitrogen, and $21.5 \%$ oxygen content ${ }^{52}$.

The full-scan X-ray photoelectron spectroscopy (XPS) survey spectra of D-series (Supplementary Information, Fig. S2) display three characteristic peaks around $286 \mathrm{eV}, 400 \mathrm{eV}$ and $532 \mathrm{eV}$, corresponding to C1s, N1s and O1s, respectively ${ }^{31,34,39,40,43-45,53}$. In addition, deconvolution of the C1s XPS spectra of CU03D,CU25D, CU50D and CU100D (Supplementary Information, Fig. S3) reveals a systematic decrease in the contributions arising from $\mathrm{C}-\mathrm{C}$ and $\mathrm{C}=\mathrm{C}(284.0 \mathrm{eV})$ (highest for CU03D) and a corresponding increase in contributions arising from $\mathrm{C}-\mathrm{N}$ and $\mathrm{C}=\mathrm{N}(286.9 \mathrm{eV})$ as well as from $\mathrm{C}-\mathrm{O}$ and $\mathrm{C}=\mathrm{O}(285.4 \mathrm{eV})$ (lowest for CU03D). Deconvolution of N1s spectra (Supplementary Information, Fig. S4) indicates the dominant population of pyrolytic nitrogen (400.1 $\mathrm{eV}$ ), while the pyridinic nitrogen $(399.1 \mathrm{eV})$ systematically decreases form $29 \%$ for CU03D to $11 \%$ for CU100D and the graphitic nitrogen $(401.5 \mathrm{eV})$ increases substantially from $9 \%$ for CU03D to $43 \%$ for CU100D. Likewise, deconvolution of O1s spectra (Supplementary Information, Fig. S5) indicates that $\mathrm{C}=\mathrm{O}(533.3 \mathrm{eV})$ increases from $78 \%$ for CU03D to $89 \%$ for CU100D, while C-O (531.5 eV) decreases from 22\% for CU03D to $11 \%$ for CU100D. The results from XPS analysis are displayed in Supplementary Information Table S2.

The Fourier Transform Infrared (FTIR) spectra of the four members of D-series (Fig. 2h) display peaks in similar positions attributed to the vibrational modes of $=\mathrm{C}-\mathrm{H}\left(2810-2197 \mathrm{~cm}^{-1}\right), \mathrm{C}=\mathrm{O}$ or $\mathrm{C}=\mathrm{N}\left(1653-1556 \mathrm{~cm}^{-1}\right)$, C-N from aromatic amine $\left(1462-1340 \mathrm{~cm}^{-1}\right), \mathrm{C}-\mathrm{N}\left(1178 \mathrm{~cm}^{-1}\right)$ and $\mathrm{C}-\mathrm{O}\left(1090-1060 \mathrm{~cm}^{-1}\right)^{48,50,54}$. Additionally, the peaks around $1600 \mathrm{~cm}^{-1}$ are related to benzene skeleton vibrations ${ }^{47}$ and the broad bands at $3028-3250$ $\mathrm{cm}^{-1}$ can be assigned to hydrophilic amine $(\mathrm{N}-\mathrm{H})$ and hydroxyl $(\mathrm{O}-\mathrm{H})$ groups, which ensure good solubility of C-dots in polar solvents ${ }^{39}$.

The zeta potential ( $\zeta$ ) of $5 \mathrm{mg} / \mathrm{ml}$ aqueous dispersions of CU03D and CU100D was estimated close to -57.2 and $-38.2 \mathrm{mV}$ respectively (Supplementary Information, Fig. S6, suggesting the presence of negatively charged 
surface groups that impart enhanced colloidal stability. In close related systems derived from precursors with $\mathrm{f}_{\mathrm{CA} / \text { urea }}=1: 3$, $\zeta$ has been estimated to be $-40 \mathrm{mV}$ and $-56 \mathrm{mV}^{55,56}$, while for $\mathrm{f}_{\mathrm{CA} / \text { urea }}=1: 6$ it was found that $\zeta=-35.7$ $\mathrm{mV}^{42}$.

The Hydrogen-1 Nuclear Magnetic Resonance ( $\left.{ }^{1} \mathrm{H}-\mathrm{NMR}\right)$ spectrum of CU50D (Supplementary Information, Fig. S7) displays two signals at $2.1 \mathrm{ppm}$ and $3.4 \mathrm{ppm}$, while the corresponding Carbon-13 Nuclear Magnetic Resonance $\left({ }^{13} \mathrm{C}\right.$-NMR) spectrum (Supplementary Information, Fig. S7) shows one peak at $169.3 \mathrm{ppm}$ (similar peaks were observed for CU03D, CU25D, CU100D). Those spectroscopic signals point to the presence of a heterocyclic compound, presumably CTA (citrazinic acid). Moreover, the peaks at $31.2 \mathrm{ppm}$ and $207 \mathrm{ppm}$ in ${ }^{13} \mathrm{C}-\mathrm{NMR}$ spectrum refer to $\mathrm{sp}^{3}$ and $\mathrm{sp}^{2}$ carbon atoms ${ }^{57}$. The Ultraviolet-visible (UV-Vis) spectra of D-series (Supplementary Information, Fig. S7) display an absorption peak at $330 \mathrm{~nm}$ and a broader one at $420 \mathrm{~nm}$, indicating the formation of CTA and its supramolecular aggregates, respectively ${ }^{30,58}$. The peak at $270 \mathrm{~nm}$ might be attributed to the to the $\pi \rightarrow \pi^{*}$ transitions of the and 4-hydroxy-1H-pyrrolo[3,4-c]pyridine-1,3,6 $(2 \mathrm{H}, 5 \mathrm{H})$-trione (HPPT) pyridone ring ${ }^{30}$.

It is well established that the thermal treatment of suitable precursors proceeds with the parallel formation of molecular fluorophores, in a manner that critically depends upon the pyrolysis conditions ${ }^{28}$. In related systems, the generation of fluorophores has been attributed to condensation and ring closure reactions that lead to pyridine-type structures ${ }^{29}$. In a close related study (fCA/urea $\left.=1: 10\right)$ High-resolution Electrospray Ionisation Mass Spectrometry (HR-LC-ESI-MS) indicated the presence of the blue emissive dye CTA (with UV absorbance peak centred at $330 \mathrm{~nm}$ ), while High Pressure Chromatography was used to separate a green emissive dye (with UV absorbance peaks centred at $270 \mathrm{~nm}$ and $410 \mathrm{~nm}$ ) that was identified as HPPT by means of Heteronuclear Multiple Bond Coherence ${ }^{30}$.

All in all, the evidence presented above indicates that the members of D-series are composed of spherical $\mathrm{C}$-dots with varying nitrogen content that possess a dense population of surface polar groups. Taken into account that the C-dots have been extensively dialysed against water over a prolonged period of time, it seems reasonable to assume that the organic fluorophores are embedded within the carbogenic structure or, alternatively, are strongly adsorbed on their surface ${ }^{59}$.

D1-series. CU50D1 was selected as a representative member of the D1 series for further characterization. The ${ }^{1} \mathrm{H}-\mathrm{NMR}$ and ${ }^{13} \mathrm{C}-\mathrm{NMR}$ spectra of CU50D1 (Supplementary Information, Fig. S8) suggest the presence of urea (5.4 ppm in ${ }^{1} \mathrm{H}-\mathrm{NMR}$ and $160.0 \mathrm{ppm}$ in $\left.{ }^{13} \mathrm{C}-\mathrm{NMR}\right)$, biuret (6.8 ppm, $7.1 \mathrm{ppm}$ and $8.5 \mathrm{ppm}$ in ${ }^{1} \mathrm{H}-\mathrm{NMR}$ and $155.8 \mathrm{ppm}$ in $\left.{ }^{13} \mathrm{C}-\mathrm{NMR}\right)$, CYA (cyanuric acid) (150.8 ppm in $\left.{ }^{13} \mathrm{C}-\mathrm{NMR}\right)$ and CA (72.9 ppm in $\left.{ }^{13} \mathrm{C}-\mathrm{NMR}\right)$. In addition, the peaks seen below $3.5 \mathrm{ppm}$ in ${ }^{1} \mathrm{H}-\mathrm{NMR}$ and within $25-35 \mathrm{ppm}$ in ${ }^{13} \mathrm{C}-\mathrm{NMR}$ correspond to the $\mathrm{sp}^{3}$ carbons while the peak at $206.9 \mathrm{ppm}$ in ${ }^{13} \mathrm{C}-\mathrm{NMR}$ spectrum suggest the presence of $\mathrm{sp}^{2}$ carbon atoms ${ }^{32,57}$. The UV absorbance spectrum of CU50D1 (Supplementary Information, Fig. S8) indicates the presence of CTA and HPPT molecular fluorophores.

The FTIR spectrum of CU50D1 (Supplementary Information, Fig. S9) shows the vibration peaks of N-H and $\mathrm{O}-\mathrm{H}\left(3418-3060 \mathrm{~cm}^{-1}\right), \mathrm{C}-\mathrm{H}\left(2810 \mathrm{~cm}^{-1}\right), \mathrm{C}=\mathrm{O}$ or $\mathrm{C}=\mathrm{N}\left(1655-1571 \mathrm{~cm}^{-1}\right), \mathrm{C}-\mathrm{N}$ from aromatic amine $\left(1412-1346 \mathrm{~cm}^{-1}\right), \mathrm{C}-\mathrm{N}\left(1147 \mathrm{~cm}^{-1}\right)$ and $\mathrm{C}-\mathrm{O}\left(1059 \mathrm{~cm}^{-1}\right)^{48,50,54,60}$. Moreover, the vibration peak ca. 1655-1571 $\mathrm{cm}^{-1}$ points to $\mathrm{C}=\mathrm{C}$ stretching, consistent with the presence of benzene skeleton rings ${ }^{36,47}$. In short, CU50D1 is composed of a mixture of CA, CYA, urea, biuret, HPPT and CTA.

F-series. In analogy to the D-series, elemental analysis (Supplementary Information, Table S3) indicates that the nitrogen content for CU03F, CU25F, CU50F and CU100F is $31 \%, 35 \%, 37 \%$ and $38 \%$, respectively and this trend is accompanied by a systematic decrease in carbon content from $36 \%$ for CU03F to $29 \%$ for CU100F. At the same time within the F-series the oxygen content remains within 28 to $30 \%$ and the hydrogen content between 4 and $5 \%$.

The XRD pattern of CU03F (Supplementary Information, Fig. S10) is similar to that seen for CU03D, showing one dominant peak attributed to the (002) lattice spacing of graphite-type structures. However, the XRD patterns of CU25F, CU50F and CU100F (Supplementary Information, Fig. S10) show additional crystalline peaks, with the most pronounced of them centred at $22.2^{\circ}, 24.6^{\circ}, 29.3^{\circ}$ and $35.4^{\circ}$, corresponding to the (112), (221), (003) and (330) crystal planes of urea.

The ${ }^{1} \mathrm{H}-\mathrm{NMR}$ spectrum of CU50F (Supplementary Information, Fig. S11) is governed by the peaks at 7.2 and $8.6 \mathrm{ppm}$ stemming from biuret, the peak at $5.6 \mathrm{ppm}$ stemming from urea, while other peaks seen below $3.5 \mathrm{ppm}$ are attributed to the $\mathrm{sp}^{3}$ carbons ${ }^{32}$. Likewise, the ${ }^{13} \mathrm{C}-\mathrm{NMR}$ spectrum of CU50F (Supplementary Information, Fig. S11) is governed by the peaks at $160.2 \mathrm{ppm}$ and $155.9 \mathrm{ppm}$, stemming from urea and biuret, respectively. The ${ }^{13} \mathrm{C}-\mathrm{NMR}$ spectrum also displays peaks in the range $25-35 \mathrm{ppm}$ and $150-210 \mathrm{ppm}$, confirming the presence of both $\mathrm{sp}^{3}$ and $\mathrm{sp}^{2}$ hybridized carbon atoms $\mathrm{s}^{57}$, while the additional signal at $151 \mathrm{ppm}$ indicates the presence of CYA ${ }^{36,61}$. The UV spectra of F-series are governed by the peaks at 250, 270, 320, $420 \mathrm{~nm}$, consistent with the presence of CTA and HPPT (Supplementary Information, Fig. S11).

In this work particular emphasis was given to the detection of melamine traces, a possible product of urea's thermolysis ${ }^{61}$ that is known to impose health risks to humans. To that end, a commercially available melamine test kit was used to confirm that the concentration of melamine in the powder was below $5 \mathrm{ppm}$. In conclusion, the evidence presented above indicates that each one of the members of F-series represents a multicomponent system comprising C-dots that coexist with HPPT, CTA, urea, CYA and biuret.

F1-series. CU50F1 was selected as a representative member of the F1 series for further characterization. The STEM image shown in Fig. 3i suggests that CU50F1 are spherical nanoparticles with diameter $15 \mathrm{~nm}$. The FTIR spectrum of CU50F1 (Fig. 3ii) close resembles that of the CYA (also displayed in Fig. 3ii for comparison) given 

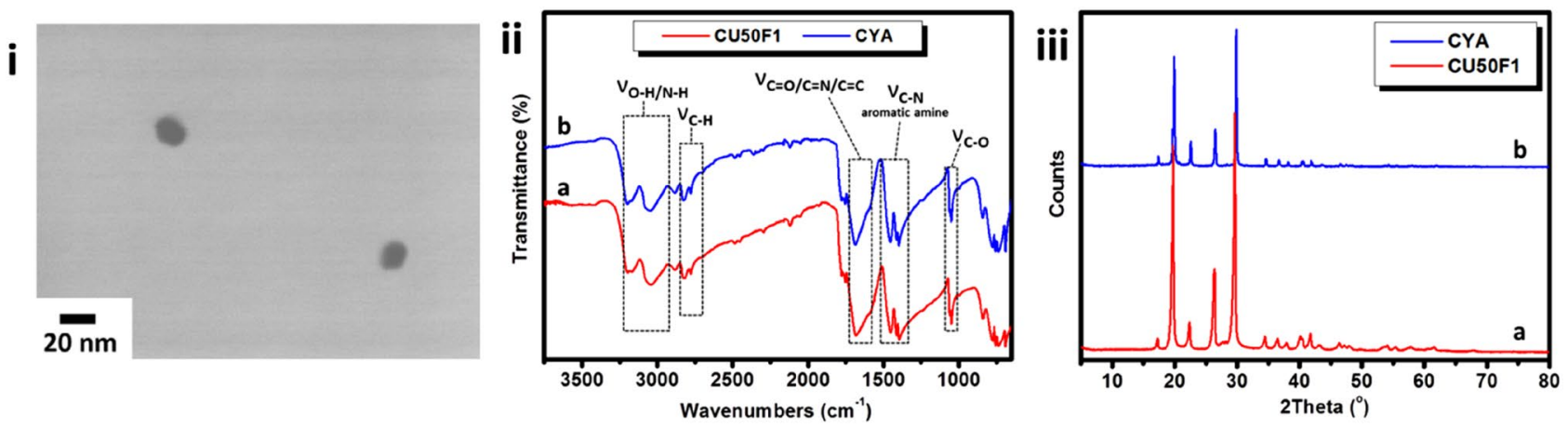

Figure 3. STEM image of CU50F1 (i) as well as FTIR spectra (ii) and XRD patterns (iii) of CU50F1 (a) and CYA (b).

that are both dominated by the vibrational peaks at $3199 \mathrm{~cm}^{-1}, 3046 \mathrm{~cm}^{-1}, 1685 \mathrm{~cm}^{-1}, 1452 \mathrm{~cm}^{-1}, 1050 \mathrm{~cm}^{-1}$ that are assigned to $\mathrm{O}-\mathrm{H}$ band of hydroxyl group, $\mathrm{N}-\mathrm{H}$ band, $\mathrm{C}=\mathrm{O}$ band as well as $\mathrm{C}-\mathrm{N}$ band of aromatic amine and $\mathrm{C}-\mathrm{O}$, respectively. Note that the oxygen content of CU50F1 is $34 \%$ compared to $28 \%$ for its preCU50F1 counterpart. Moreover, the ${ }^{13} \mathrm{C}-\mathrm{NMR}$ spectrum of CU50F1 shows a characteristic peak at $151.1 \mathrm{ppm}$, corresponding to the main peak seen for CYA (Supplementary Information, Fig. S12). The close matching between the XRD patterns of CU50F1 and CYA (Fig. 3iii) further supports the conclusion that CU50F1 incorporates significant amounts of CYA crystals. A similar system comprising CYA-rich C-dots has been previously prepared via infrared-assisted pyrolysis of a mixture comprising CA and urea with $\mathrm{f}_{\mathrm{CA} / \mathrm{urea}}=1: 3^{36}$.

\section{Photoluminescence properties in water}

CU03D exhibits excitation wavelength dependent emission characteristic of its carbogenic nature, while for CU25D, CU50D and CU100D contributions stemming from the CTA units $\left(\lambda_{\mathrm{em}}=390 \mathrm{~nm}\right)$ are also present (Fig. $4 \mathrm{a}-\mathrm{d})$. Furthermore, for all samples an emissive signal consistent with HPPT $\left(\lambda_{\text {em }}=525 \mathrm{~nm}\right)$ can be observed. The maximum PL emission was recorded at $\lambda_{\mathrm{ex}}=460 \mathrm{~nm}$ for CU03D, but at $\lambda_{\mathrm{ex}}=420 \mathrm{~nm}$ for the other three members of the D-series. In moving form CU03D towards CU100D, a systematic blue shift is observed at $\lambda_{\mathrm{ex}}=460 \mathrm{~nm}$ (Supplementary Information, Fig. S13). It has been suggested that even hybridization of frontier orbitals between edge $\mathrm{N}$ atoms and graphene quantum dots (GQDs) results in blue-shifting ${ }^{62}$. As shown in Fig. 4e, the QY falls within 1-4\% for CU03D, 1-5\% for CU25D, 2-7\% for CU50D and 2-9\% for CU100D, thus exhibiting a systematic enhancement with nitrogen content. As expected, the PL curves of CU50D1 (Fig. 4f) are dominated by two excitation wavelength independent contributions stemming from CTA $\left(\lambda_{\mathrm{em}}=390 \mathrm{~nm}\right)$ and $\operatorname{HPPT}\left(\lambda_{\mathrm{em}}=525 \mathrm{~nm}\right)$, respectively.

The CTA and HPPT emissive signals are hard to discern for CU03F, but are clearly observed for CU25F, CU50F and CU100F (Fig. 5a-d). All members of F-series also show pronounced excitation wavelength dependent emissions and the QY falls within 3-28\% for CU03F, 11-28\% for CU25F, 12-32\% for CU50F and 13-30\% for CU100F (Fig. 5e). Those values are much higher compared to the $\mathrm{D}$-series as a direct consequence of the presence of fluorophores molecules. A survey in the literature suggests that QY of C-dots derived by identical precursor mixtures with $\mathrm{f}_{\mathrm{CA} / \mathrm{urea}}=1: 3$ vary considerably from $9 \%$, to $27 \%$ up to $73 \%\left(\lambda_{\text {ex }}=410 \pm 10 \mathrm{~nm}\right)^{51,57,63,64}$.

It is well-understood that such pronounced discrepancies in QY might originate from variations related to the purification/size separation procedures that, in turn, largely determine the amount of fluorophores that are removed away from the system. Our experimental protocol allows a quantitative assessment of the impact of molecular fluorophores on the emission of C-dots based dispersions, in the sense that a comparison between $\mathrm{D}$ and $\mathrm{F}$ series indicates that the presence of unbound molecular fluorophores improves the QY by a factor between three to five. We note that all members of F-series apart form C-dots and organic fluorophores, also contain urea, biuret and citric acid that do not affect the PL intensity and CYA that is known to quench the PL of C-dots.

Interestingly, CU50F1 exhibits excitation wavelength dependent PL emission (Fig. 5f) with QY equal to 10, 32,10 and $3 \%$ at $\lambda_{\text {ex }}=365,425,480,510 \mathrm{~nm}$, respectively. For reference, the CYA-enriched C-dots previously reported exhibit QY between 8 to $16 \%\left(\lambda_{\text {ex }}=360 \mathrm{~nm}\right)$, displaying asymmetric lamps at 450 and $520 \mathrm{~nm}^{36}$ that close resemble those seen in Fig. $6 \mathrm{f}$. In principle, with respect to the PL mechanism of C-dots, three emissive modes have been identified originating from surface defects, the presence of isolated $\mathrm{sp}^{2}$ islands with $\mathrm{sp}^{3}$ domains and crosslink-enhanced emissions, respectively ${ }^{65,66}$.

The average fluorescence lifetime ( $\left.\tau_{\mathrm{avg}}\right)$ at $\lambda_{\mathrm{ex}}=375$ and $450 \mathrm{~nm}$ was found to be between $7.5 \mathrm{~ns}$ to $9.2 \mathrm{~ns}$ for D-series (Supplementary Information, Fig. S14) and between $5.6 \mathrm{~ns}$ to $7.0 \mathrm{~ns}$ for the F-series (Supplementary Information, Fig. S15). A previous study reported that C-dots derived via pyrolytic treatment $\left(1 \mathrm{~h}, 250^{\circ} \mathrm{C}\right)$ of CA/ urea mixture with $\mathrm{f}_{\mathrm{CA} / \mathrm{urea}}=1: 3$ shows $\tau_{\text {avg }}=6.7 \mathrm{~ns}$, while hydrothermal treatment of the same precursor mixture resulted in the generation of N-GQDs with $\tau_{\mathrm{avg}}=8.1 \mathrm{~ns}^{31,67}$. At the same time, a single exponential PL decay with lifetime of $6.4 \mathrm{~ns}$ has been demonstrated for $\mathrm{CTA}^{68}$, while C-dots are known to exhibit multi-exponential delay stemming from heterogeneous emitting states in a single C-dot or within a larger C-dot ensemble ${ }^{69}$. 

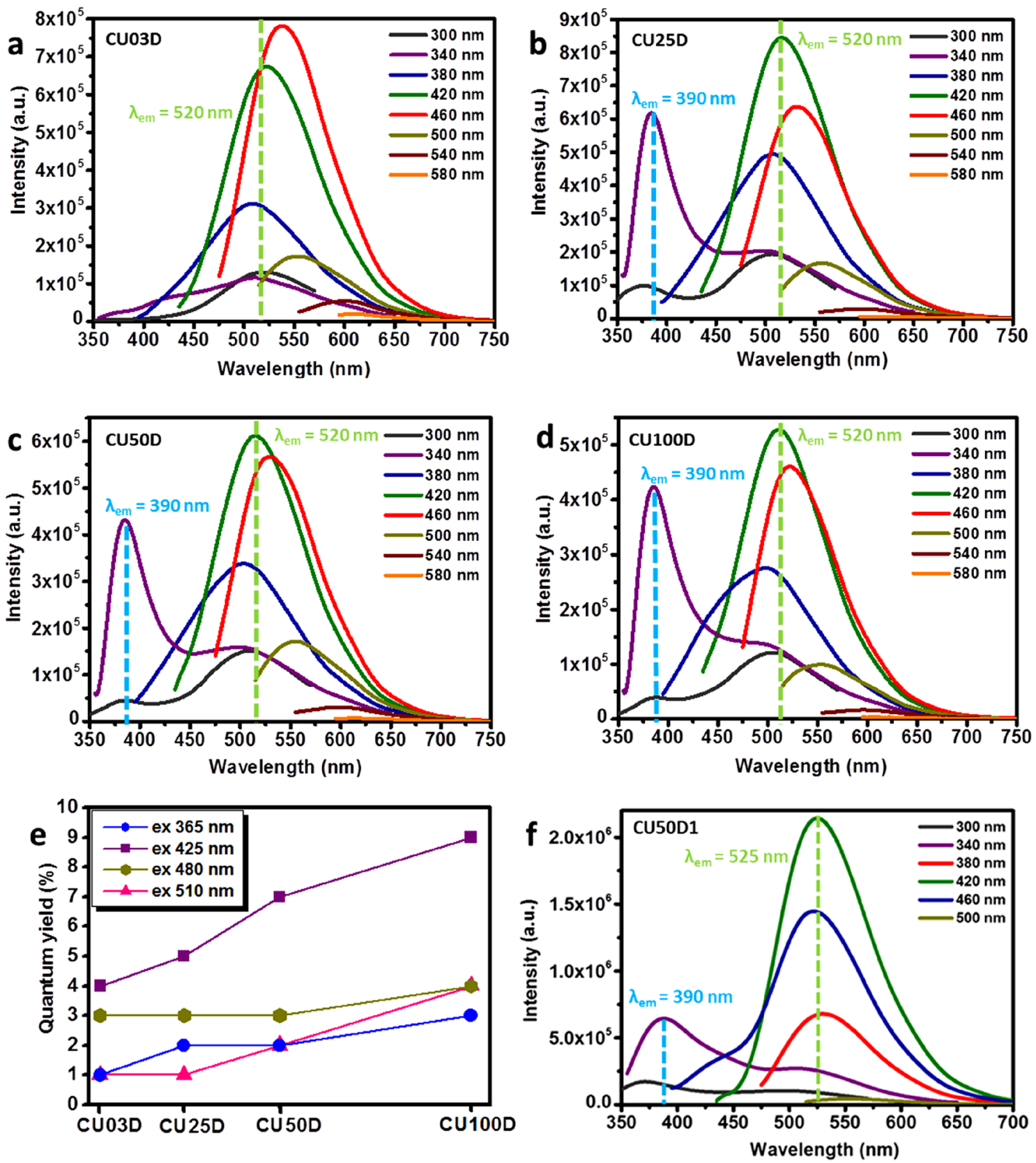

Figure 4. Fluorescence emission spectra (under the various excitation wavelengths indicated) of $0.1 \mathrm{mg}$ / $\mathrm{mL}$ aqueous dispersions of CU03D (a), CU25D (b), CU50D (c) and CU100D (d), the graph showing the corresponding QY values at $\lambda_{\mathrm{ex}}=365 \mathrm{~nm}$ (circles), $425 \mathrm{~nm}$ (squares), $480 \mathrm{~nm}$ (diamonds), 510 (triangles) (e) as well as the fluorescence emission spectra (under the various excitation wavelengths indicated) of $0.1 \mathrm{mg} / \mathrm{mL}$ aqueous dispersion of CU50D1 (f).

\section{Nanopowders}

All members of D-series as well as CU03F are not photoactive in their solid state, presumably due to pronounced self-quenching effects. In contrast, CU25F, CU50F and CU100F nanopowders show colour-tuneable characteristics in the sense that they adopt blue, green and red colour when illuminated by violet, blue and green radiation, respectively (Fig. 6a-c). The fluorescence behavior of F- powders originates from the presence of C-dots, given that fluorescent microscopy images of urea/ CA precursor powders do not show any fluorescence, while the D1-powders show only blue fluorescence under identical conditions. The emissive peaks of those nanopowders are broad (in line with the behaviour previously reported ${ }^{74}$ ) and their intensity systematically increases with the nitrogen content as shown in Fig. 6d-g.

The PL lifetime decay of the powders at $\lambda_{\mathrm{ex}}=375 \mathrm{~nm}$ can be fitted by a bimodal function, showing $\tau_{\mathrm{avg}}$ close to $5.85 \mathrm{~ns}$ for CU25F, $5.95 \mathrm{~ns}$ for CU50F and $6.45 \mathrm{~ns}$ for CU100F, while similar trends were observed at $\lambda_{\mathrm{ex}}=450$ $\mathrm{nm}$ (Supplementary Information, Fig. S16). 

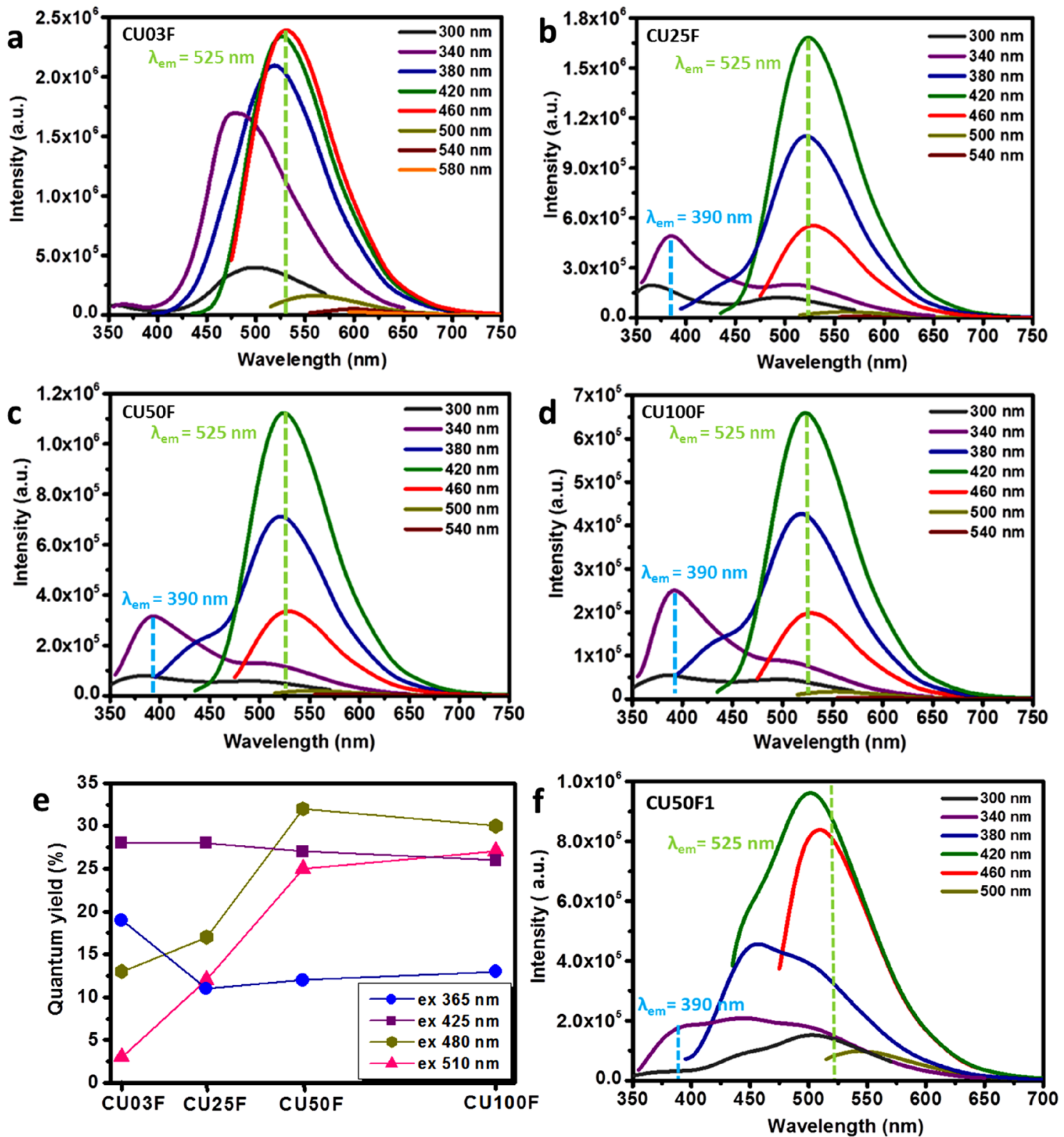

Figure 5. Fluorescence emission spectra (under the various excitation wavelengths indicated) of $0.1 \mathrm{mg} / \mathrm{mL}$ aqueous dispersions of CU03F (a), CU25F (b), CU50F (c) and CU100F (d), the graph presenting the QY of CU03F, CU25F, CU50F and CU100F at $\lambda_{\mathrm{ex}}=365 \mathrm{~nm}$ (circles), $425 \mathrm{~nm}$ (squares), $480 \mathrm{~nm}$ (diamonds), $510 \mathrm{~nm}$ (triangles) (e) and fluorescence emission spectra (under the various excitation wavelengths indicated) of $0.1 \mathrm{mg} /$ $\mathrm{mL}$ aqueous dispersions of CU50F1 (f).

Effective strategies to generate fluorescent C-dots based nanopowders rely on the use of a suitable diluent powder ${ }^{23}$, the engineering of a carbogenic coating on the surface of nanoparticles ${ }^{70}$ or microspheres ${ }^{71}$, the presence of long aliphatic chains on the surface of the C-dots ${ }^{72}$ and effects related to aggregation-induced emission ${ }^{73}$. A previous study discloses PL nanopowders with decreased $\mathrm{sp}^{2}$ domains derived pyrolytically from mixtures with $\mathrm{f}_{\mathrm{CA} / \text { urea }}=1: 26$; however this strategy depends on a rather tedious purification protocol by means of grinding to fine powder, dispersion in ethanol, centrifugation, dispersion in water, dialysis, filtration and freeze-drying ${ }^{74}$.

In this work we demonstrate a facile approach to generate PL nanopowders by employing precursor systems comprising extreme excess of urea, followed by a single filtration step as the sole size separation process. The role of urea is triple: it serves as the building block of the carbogenic core, as a reactant for the synthesis of molecular fluorophores, while its thermolysis products and its unreacted fraction are used as the diluent materials that eliminate undesired self-quenching effects. In that sense our strategy demonstrates a cost effective pathway towards the production of functional materials for highly demanding applications.

For convenience, Table 1 summarises the composition and performance characteristics of the four families of PL materials synthesised in this study. 
a

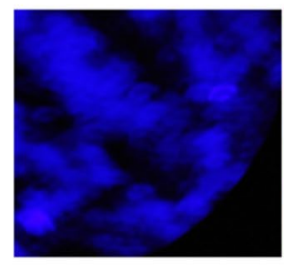

b

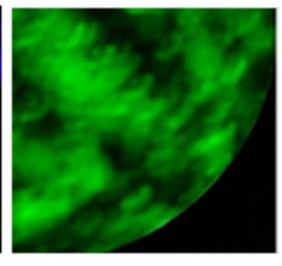

C

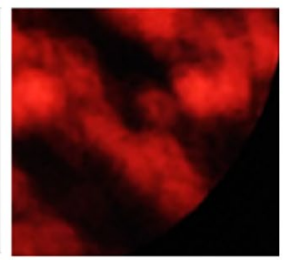

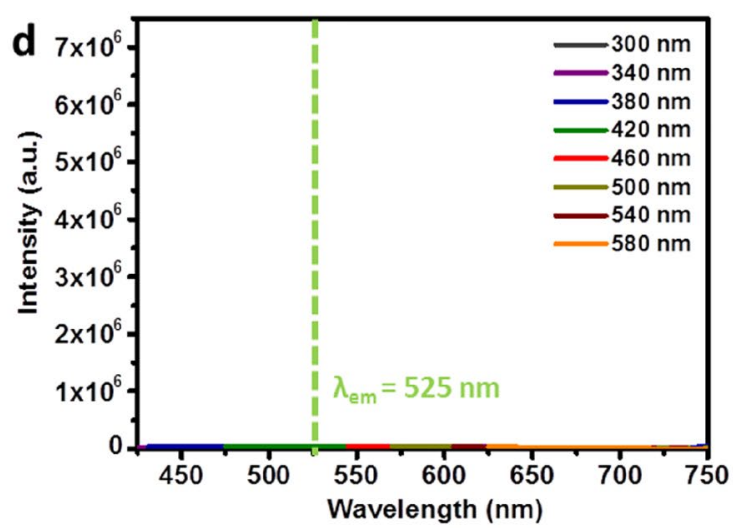
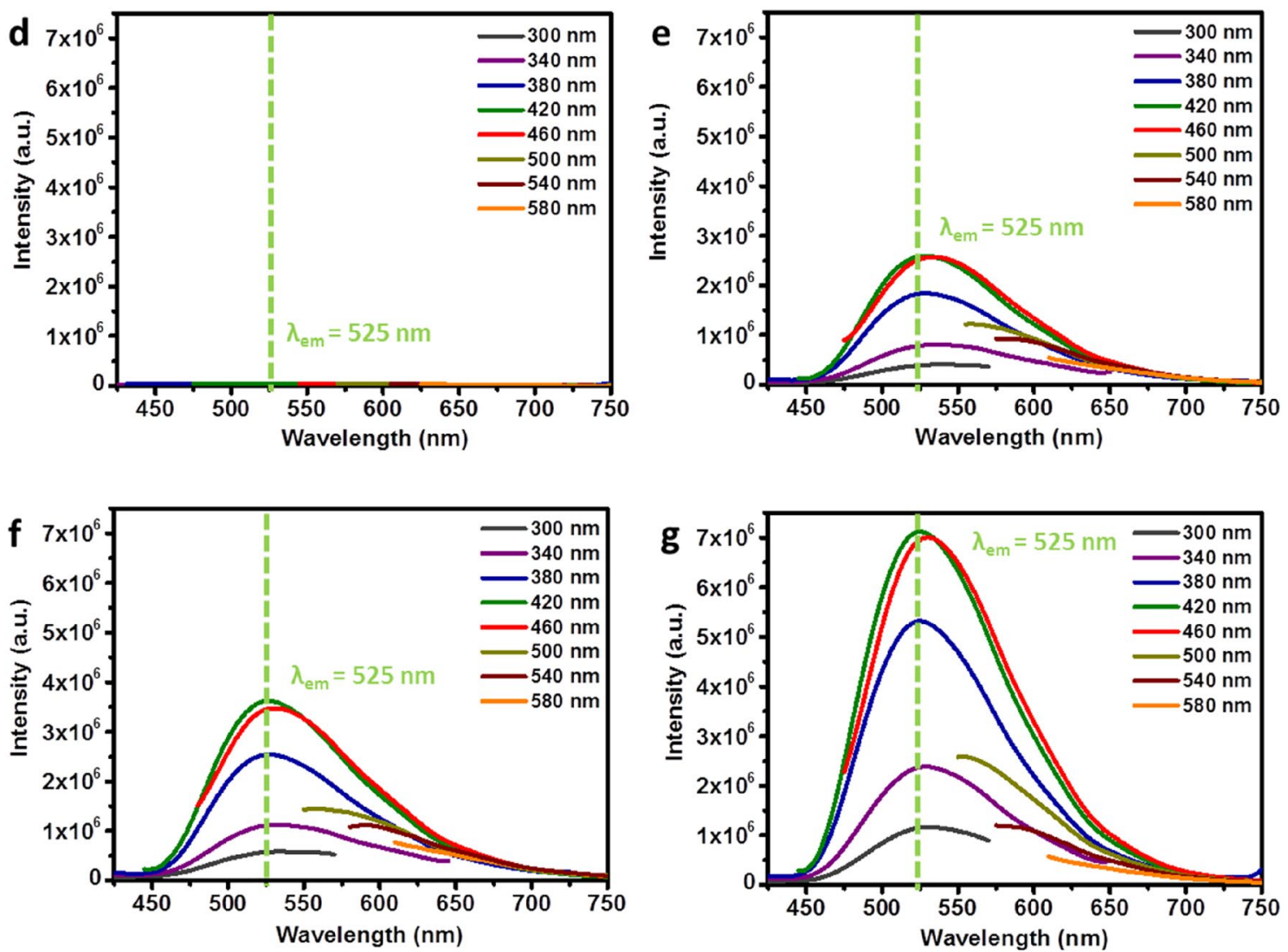

Figure 6. Fluorescent microscopy images of CU100F nanopowders on a glass slide illuminated using a violet (a), blue (b) and green (c) excitation wavelength and the fluorescence emission spectra (under the various excitation wavelengths indicated) of CU03F (d), CU25F (e), CU50F (f) and CU100F (g) nanopowders.

\begin{tabular}{|l|l|l|l|}
\hline Type of material & Composition & Liquid state, QY & Solid state PL \\
\hline \multirow{2}{*}{ D-series } & \multirow{3}{*}{ C-dots, CTA and HPPT entrapped in C-dots } & CU03D, 1-4\% & No \\
\cline { 3 - 4 } & & CU50D, 2-7\% & No \\
\cline { 3 - 4 } & & CU25D, 1-5\% & No \\
\cline { 3 - 4 } & CYA, CA, urea, biuret, HPPT & Yes & Yes \\
\hline \multirow{2}{*}{ F-series } & \multirow{2}{*}{ C-dots, CYA, CTA, urea, biuret, HPPT } & CU03F, 3-19\% & No \\
\cline { 3 - 4 } & & CU25F, 11-28\% & Yes \\
\cline { 3 - 4 } & & CU50F, 12-32\% & Yes \\
\cline { 3 - 4 } & & CU100F, 13-30\% & Yes \\
\hline F1-series & CYA-rich C-dots & CU50F1, 3-32\% & No \\
\hline
\end{tabular}

Table 1. Composition and PL behaviour of D-, D1-, F-, F1- series. 


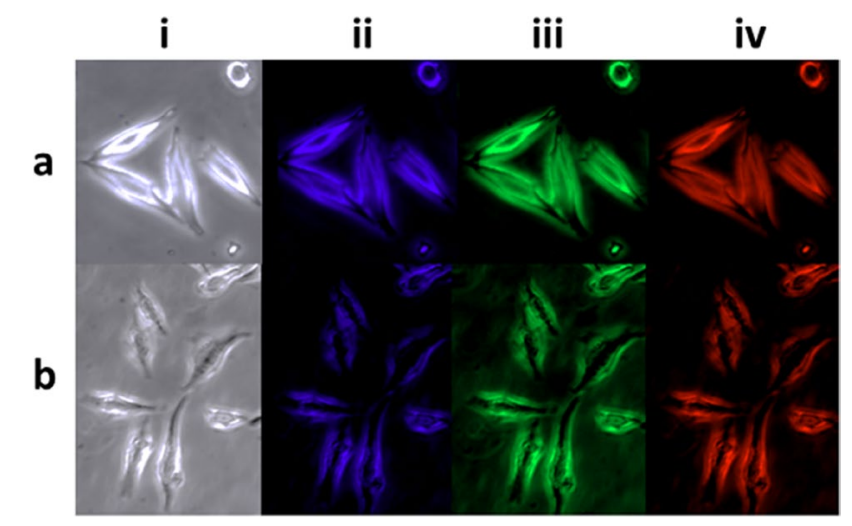

Figure 7. Fluorescent microscope images of HeLa cell line incubated with $100 \mu \mathrm{g} / \mathrm{mL}$ of CU100D (a) and CU100F (b) under the bright field (i) as well as the UV (ii), blue (iii) and green (iv) excitation wavelengths.

\section{Toxicity/Bioimaging}

The toxicity of D-series and F-series was evaluated with respect to HeLa cells using standard MTT (3-(4,5-dimethylthiazolyl-2)-2,5-diphenyltetrazolium bromide) assays. The results indicated that the mortality of HeLa cells incubated for $24 \mathrm{~h}$ with C-dots (at concentrations up to $1 \mathrm{mg} / \mathrm{mL}$ ) was lower that $10 \%$ (Supplementary Information, Fig. S17). Suffice it to say that such low toxicity values, rarely seen for other classes of photoactive materials, is highly desirable for biomedical applications, although experimental evidence suggests that the surface functional groups might have a pronounced effect on the cytotoxicity of C-dots ${ }^{52,63}$. Moreover, fluorescent images (Fig. 7) indicated that upon incubation, C-dots become internalised by HeLa cells, illuminating both the cytoplasm and the cells membranes. Those promising results indicate that both $\mathrm{D}$ and $\mathrm{F}$ series are ideal candidates for multicolour imaging and cell labelling given that they emit strong PL signals under a wide range of excitation wavelengths.

The F-series shows excellent antimicrobial properties against Escherichia coli (causing reduction in bacterial colonies between $99.5 \%$ and $99.9 \%$ ) and Staphylococcus aureus strain (causing reduction in bacterial colonies between 99.2\% and 99.9\%) (Supplementary Information, Table S4). Likewise, the D-series exhibits significant antimicrobial properties against E. coli and S. aureus that is more pronounced for CU03D, CU25D, CU50D, but falls to 79\% against E. coli for CU100D. Note that derivatives of CTA and molecules structurally similar to HPPT as well as CA are known to exhibit significant antimicrobial properties ${ }^{75-77}$.

\section{Conclusions}

In conclusion, we provide an easy-to-follow roadmap to synthesise a large gallery of photoactive materials derived via the thermal treatment of CA and urea, by varying the molar ratio of the components in the precursor mixture and by employing two standard size separation strategies, i.e. dialysis and filtration. In the latter case we report the preparation of PL nanoparticles derived from both the filtrate and the residue, thus suggesting an eco-friendly synthetic approach with minimal waste. Apart from demonstrating the preparation of four families of highly fluorescent aqueous dispersions, we also present the synthesis of colour-tuneable, photoluminescent nanopowders that are derived pyrolytically from mixtures containing extreme excess of urea, followed by a single filtration step. Significantly, the powders that have been subjected to extensive purification (a rather tedious and time consuming procedure) do not exhibit fluorescence emission, while the powders processed by simple filtration (a simple and fast procedure) are ideal candidates for applications related to solid state emission such as fingerprint powders, light emitting diodes, etc. Compared to previous reports, our approach represents by far the most cost and time effective synthetic route for the preparation of highly PL nanopowders based on C-dots.

\section{Methods}

Materials. Urea (purity 99.0-100.5\%) and citric acid (CA) monohydrate (purity 99.5\%) were purchased from Sigma Aldrich and Alfa Aesar, respectively. Nitric acid $\left(\mathrm{HNO}_{3}\right) 70 \%$ and water (purity $\left.\geq 99.9\right)$ were bought from Fischer Chemical. The cellulose grade one paper filters $(11 \mu \mathrm{m}$ particle retention) were supplied by Whatman (GE Healthcare Life Sciences). The SnakeSkin Dialysis Tubing membrane $3.5 \mathrm{kDa}$ molecular weight cut-off (MWCO, $35 \mathrm{~mm}$ ) was purchased from Thermo Fisher Scientific.

Preparation of D-series, D1-series, F-series and F1-series. The CA monohydrate was mixed with urea and the mixture was placed into a furnace programmed to rise to $230{ }^{\circ} \mathrm{C}$ at a rate of $1{ }^{\circ} \mathrm{C} / \mathrm{min}$ and was then left at $230^{\circ} \mathrm{C}$ for $1 \mathrm{~h}$. Four different molar ratios of $\mathrm{CA}$ to urea $\mathrm{f}_{\mathrm{CA} / \text { urea }}$ equal to 1:3, 1:25, 1:50 and 1:100 were used to form the products CU03, CU25, CU50 and CU100, respectively. The clustered solid materials received were ground to fine powders using a mortar and pestle. The ground material was dispersed in water and was extensively dialysed against water for 10 weeks using SnakeSkin membrane with $3.5 \mathrm{kDa}$ MWCO to generate the D-series (CU03D, CU25D, CU50D and CU100D). The run-off substances during the first month were collected to form the D1 series (CU03D1, CU25D1, CU50D1 and CU100D1). Alternatively, the pyrolysis products were dispersed in water and passed through cellulose grade one paper filters ( $11 \mu \mathrm{m}$ particle retention) to give rise 
to the F-series (CU03F, CU25F, CU50F and CU100F). The residues on the filters (the preF1-series, comprising preCU03F1, preCU25F1, preCU50F1 and preCU100F1) were oxidised with $3 \mathrm{M}$ nitric acid for $18 \mathrm{~h}$, giving rise to the F1-series (CU03F1, CU25F1, CU50F1 and CU100F1). All samples were freeze-dried and stored in a dry environment before use.

Characterization. CHNS Elemental Analyzer (Flash 2000) equipped with a column for oxygen determination was calibrated against 2,5-(Bis(5-tert-butyl-2-benzo-oxazol-2-yl)thiophene (Thermo Scientific, UK). The $\mathrm{C}, \mathrm{H}, \mathrm{N}$ analysis was carried out in aluminium pans, while oxygen analysis in silver pans (both types of pans were received from CE Instruments). The ${ }^{1} \mathrm{H}$ and ${ }^{13} \mathrm{C} N M R$ spectra were recorded using Bruker Advance-III spectrometer operating at $300 \mathrm{MHz}$ and $75 \mathrm{MHz}$, respectively by using tetramethylsilane (TMS) as an internal standard. All samples were dissolved in deuterated dimethyl sulfoxide (d-DMSO, Cambridge Isotopes Laboratories Inc.) and scanned 128 times $\left({ }^{1} \mathrm{H}-\mathrm{NMR}\right)$ or 1024 times $\left({ }^{13} \mathrm{C}-\mathrm{NMR}\right)$ at ambient temperature, using a $5 \mathrm{~mm}$ NMR tube (Wilmad LabGlass, USA). For comparison the NMR spectra of biuret (Alfa Aesar), CYA (Sigma Aldrich), CTA (Sigma Aldrich), CA (Alfa Aesar) and urea (Sigma Aldrich) were also collected. FTIR spectra were recorded by means of ThermoFisher Scientific Ltd Nicolet IS5 spectrometer. Samples were scanned 128 times at a resolution of $2 \mathrm{~cm}^{-1}$, within the range of 3750-650 $\mathrm{cm}^{-1}$. XRD patterns were obtained using a Bruker D2 Phaser equipped with a Lynxeye 1-dimensional detector. The wavelength of the $\mathrm{Cu}$ Ka radiation was $0.154 \mathrm{~nm}$. Samples were scanned for $30 \mathrm{~min}$, within the $2 \theta$ range from $5^{\circ}$ to $80^{\circ}$. Unisensor Melamine Sensor kit was used for the detection of melamine. To that end $200 \mu \mathrm{l}$ of $5 \mathrm{wt} \%$ aqueous dispersion of the powders were transferred to a microwell containing gold nanoparticles functionalised with antibody showing high affinity for melamine. A colour development (pink line) within the test zone of a dipstick comprising capture zones, is the signature of a melamine-free sample. The test sensitivity for aqueous solutions is $250 \mathrm{ppb}$. Zeta Potential ( $\zeta)$ measurements were made using a Zetasizer Ultra (Malvern Panalytical, Ltd) which includes a $10 \mathrm{~mW}$ He-Ne laser operating at $\lambda=633 \mathrm{~nm}$. Dust-free solutions were obtained by filtration through Nylon membrane filters with a pore size of $(0.45 \mu \mathrm{m})$ (GE Nylon Syringe Filter). The concentration of the dispersions was $5 \mathrm{mg} / \mathrm{ml}$ and the temperature was set to $25^{\circ} \mathrm{C}$. The electrophoretic mobility was converted into Zeta Potential assuming Smoluchowski approximation. Fluorescence microscopy images were obtained using a Zeiss Axio Scope A1 microscope equipped with band-pass filters. Three excitation wavelengths were used 350 (ultraviolet), 395 (blue) and 590 (green) nm. STEM experiments were performed by using JEOL-JSM-7001F. The STEM detector, high vacuum mode and 20-30 kV accelerating voltages were used during experiments. Samples for STEM experiments were prepared by drying a drop of aqueous solutions with concentrations of about $1 \mathrm{mg} / \mathrm{mL}$ on carbon-coated copper grids at room temperature. The nanoparticle sizes were analyzed by means of image analysis software Image (Version 1.52a, National Institute of Health, USA). HRTEM experiments were performed by using a JEOL JEM-ARM 200CFEG UHR-TEM (equipped with STEM, Cs corrected STEM, EDS, Gatan Quantum GIF and Digital CCD Camera). Ultraviolet-visible (UV-Vis) spectra of aqueous dispersion were recorded at room temperature using the UV-3600 spectrophotometer (SHIMADZU,USA). Diluted aqueous solutions with concentration $0.1 \mathrm{mg} /$ $\mathrm{mL}$ were placed in Hellma Analytics quartz cuvette $(1.0 \mathrm{~cm}$ pathlength). XPS analysis was carried out using ESCA2SR spectrometer (Scienta Omicron $\mathrm{GmbH}$ ) equipped with a monochromatic $\mathrm{Al} \mathrm{Ka} \mathrm{X}$-ray radiation source. $(1486 \mathrm{eV})$ with $15 \mathrm{~mA}$ emission at $300 \mathrm{~W}$. Any differential charging effects were removed using a charge neutralising low-energy electron gun (FS40A, PREVAC) under X-ray illumination. High resolution core level scans were measured with a pass energy of $20 \mathrm{eV}$, and overview surveys with $80 \mathrm{eV}$ pass energy. Gaussian-Lorentzian peak shapes were used in CASAXPS for spectral deconvolution. Fluorescence spectroscopy and QY. Fluorescence spectra of solutions and nanopowders were recorded at room temperature using a Horiba Fluoromax spectrofluorometer and the samples were excited at wavelengths between 320-500 nm, with $30 \mathrm{~nm}$ increment. For the solid state characterization, the sample holder was placed at 30 degree angle with respect to the incident beam. The relative $Q Y$ of C-dots solutions were calculated using the Equation :

$$
\mathrm{QY}=\mathrm{QY} \mathrm{R}_{\mathrm{R}} \times\left(\frac{\mathrm{m}}{\mathrm{m}_{\mathrm{R}}}\right) \times\left(\frac{\eta^{2}}{\eta_{\mathrm{R}}^{2}}\right)
$$

where $Q Y_{R}$ is the $\mathrm{QY}$ of the reference dye, $\mathrm{m}$ and $\mathrm{m}_{\mathrm{R}}$ refer to the slope calculated from a linear regression of the examined material and the reference dye, $\eta^{2}$ and $\eta_{R}^{2}$ are the refractive indexes of the solvents used for the examined material and the reference dye, respectively. The anthracene $(\mathrm{QY}=0.27)$, fluorescein $(\mathrm{QY}=0.79)$, rhodamine $6 \mathrm{G}$ $(\mathrm{QY}=0.95)$ and rhodamine $\mathrm{B}(\mathrm{QY}=0.70)$ were dissolved in ethanol and used as standard reference dyes with excitation wavelengths $365 \mathrm{~nm}, 425 \mathrm{~nm}, 480 \mathrm{~nm}$ and $510 \mathrm{~nm}$, respectively. Anthracene was purchased from Sigma Aldrich while the other dyes were received from Alfa Aesar). All the measurements of absorbance and integrated PL intensity were conducted using a Hellma Analytics quartz cuvette with $1.0 \mathrm{~cm}$ pathlength. Additionally, the absorbance values were kept below 0.10 , in order to minimize re-absorption effects.

Fluorescence lifetimes. Fluorescence lifetime decays were recorded using Edinburgh Instruments LifeSpec-II equipped with two high-repetition rate picosecond pulsed diode lasers (EPL-375 and EPL-450) operating at $375 \mathrm{~nm}$ and $450 \mathrm{~nm}$, respectively. The detector signals were processed using Time-correlated Single Photon Counting (TCSPC) data acquisition unit. The PL lifetime decays for aqueous dispersions were collected with 10,000 peak counts in quartz cuvette $(10 \mathrm{~mm}$ path length) at room temperature over $200 \mathrm{~ns}$ time range. The PL lifetime decays of solid powders were collected in quartz slides ( $0.5 \mathrm{~mm}$ pathlength) with the same parameters. The instrument response function (IRF) was recorded at the same experimental parameters, using a dilute aqueous dispersion of colloidal silica (Ludox HS-30) for the solutions and empty quartz slides for the powders. The average PL lifetimes $\left(\tau_{\text {avg }}\right)$ were calculated from the Equation: 


$$
\tau_{\mathrm{avg}}=\frac{\sum \alpha_{i} \tau_{i}^{2}}{\Sigma \alpha_{i} \tau_{i}}
$$

where $\tau_{i}$ is the time component of multiexponential decay fitting and $\alpha_{i}$ is the fractional weight for each time component).

Cytotoxicity studies were assessed with the use of the standard MTT (3-(4,5-dimethylthiazolyl-2)-2,5-diphenyltetrazolium bromide) assay (Sigma Aldrich) and the epithetical HeLa cervix cancer cell line. This immortalised cell line is very well characterised with its full genome being sequenced ${ }^{78}$ and is considered as a model line by regulatory odies such as the OECD, being widely used for the assessment of nanoparticles toxicity ${ }^{79,80}$. The HeLa cells were cultured in Dulbecco's Modified Eagle Medium (DMEM, ThermoFisher Scientific) supplemented with 10\% Fetal Bovine Serum (FBS, ThermoFisher Scientific) and 1\% Penicilin-Streptomycin (10,000 U/mL, ThermoFisher Scientific). Initially, $50 \mu \mathrm{L}$ of cell suspensions with the density $5 \times 10^{4} \mathrm{cells} / \mathrm{mL}$ were seeded in a 96-well plate and left in the incubator $\left(37^{\circ} \mathrm{C}, 5 \% \mathrm{CO}_{2}\right)$ overnight to promote adhesion of the cells to the bottom of each well. After $24 \mathrm{~h}$, the cells were incubated with various concentrations of C-dots solutions $(5-1000 \mu \mathrm{g} /$ $\mathrm{mL}$ in DMEM) for $24 \mathrm{~h}$. Subsequently, $20 \mu \mathrm{L}$ of MTT solution $(5 \mathrm{mg} / \mathrm{mL})$ was added into each well and left for $2 \mathrm{~h}$ of incubation. In the last step, $150 \mu \mathrm{L}$ of lysis buffer $(0.7 \mathrm{M})$ was added into each well to dissolve formazan crystals and incubated for further $3 \mathrm{~h}$. Finally, the optical density (OD) of each sample was recorded using a microplate reader (ThermoFisher Scientific, UK) at a wavelength $595 \mathrm{~nm}$. The cell viability was calculated based on the Equation:

$$
\text { Cell viability }[\%]=\frac{\mathrm{OD} \text { treated }}{\mathrm{OD} \text { control }} \times 100
$$

where $\mathrm{OD}_{\text {treated }}$ and $\mathrm{OD}_{\text {control }}$ were obtained in the presence and the absence of C-dots, respectively. All assays were performed at least three times and an average value was calculated). In vitro fluorescence imaging. The HeLa cells cultured in DMEM supplemented with 10\% FBS (v/v) and 1\% Penicilin-Streptomycin (v/v) were seeded in 6-well plate and left overnight in the incubator at $37^{\circ} \mathrm{C}\left(5 \% \mathrm{CO}_{2}\right)$. Afterwards, $100 \mu \mathrm{g} / \mathrm{mL}$ C-dots solutions were added to each well with the HeLa cells and incubated for further $24 \mathrm{~h}$. Then, the media was removed and the cells were washed three times with phosphate buffer saline (PBS) buffer ( $\mathrm{pH} \mathrm{7.2)} \mathrm{to} \mathrm{remove} \mathrm{not} \mathrm{internalized}$ C-dots. The fluorescence imaging in live cells was performed under bright field as well as with $\lambda_{\text {ex }}=366 \mathrm{~nm}, 488$ $\mathrm{nm}$ and $512 \mathrm{~nm}$. Antimicrobial studies. A. Culturing Method: The method has been described in detail elsewhere ${ }^{81}$. In brief, nutrient broth was inoculated with a single loop of bacteria and incubated at $37^{\circ} \mathrm{C}$, for $24 \mathrm{~h}$ at $200 \mathrm{rpm}$ in a SciQuip Incu-Shake MIDI orbital shaker (SciQuip Ltd, Newtown,Wem, Shropshire, UK). Subsequently, the bacteria cultures were centrifuged twice, the supernatant was discarded, and the resuspended cultures were diluted in nutrient broth to obtain an absorbance reading equivalent to a $0.5 \mathrm{McF}$ arlane standard as recorded by Biochrom WPA S800 visible spectrophotometer. B. Antimicrobial testing method: $0.1 \mathrm{~g} \pm 0.01 \mathrm{~g}$ of C-dots was dispersed in $1 \mathrm{ml}$ nutrient broth and the dispersion was autoclaved. Subsequently, $8 \mathrm{ml}$ sterile nutrient broth and $1 \mathrm{~mL}$ of strain were added to each dispersion and placed into a shaking incubator set to $200 \mathrm{rpm}$ at $37^{\circ} \mathrm{C}$. After $24 \mathrm{~h}$ of incubation, $1 \mathrm{~mL}$ aliquot was removed from each suspension and was serially diluted by adding $100 \mu \mathrm{L}$ of it into $900 \mu \mathrm{L} 1 / 4$ strength Ringer's solution. This allowed an order of magnitude dilution at a time and this process was repeated several times so that the number of colonies would fall within the range 30-300. To that end, $100 \mu \mathrm{L}$ of each one of the series of the diluted suspensions was spread onto nutrient agar plates using a sterile plastic spreader. Plates were incubated for $24 \mathrm{~h}$ at $37^{\circ} \mathrm{C}$, then the number of colonies was determined. The percentage decrease in comparison to the control plate was calculated using the Equation:

$$
\text { Bacterial colony decrease }[\%]=\frac{\text { Control }- \text { Test }}{\text { Control }} \times 100
$$

where Control and Test stands for the number of colonies in the plates in the absence and in the presence of C-dots, respectively under otherwise identical conditions.

For each type of $\mathrm{C}$-dots the experiments were conducted in triplicates and the average values were determined.

Received: 10 January 2021; Accepted: 8 March 2021

Published online: 18 May 2021

\section{References}

1. Zhang, X. et al. Natural-product-derived carbon dots: from natural products to functional materials. Chemsuschem 11, 11-24 (2018).

2. Meng, W. et al. Biomass-derived carbon dots and their applications. Energy Environ. Mater. 2, 172-192 (2019).

3. Krysmann, M. J., Kelarakis, A. \& Giannelis, E. P. Photoluminescent carbogenic nanoparticles directly derived from crude biomass. Green Chem. 14, 3141-3145 (2012)

4. Zhu, L. L., Yin, Y. J., Wang, C. F. \& Chen, S. Plant leaf-derived fluorescent carbon dots for sensing, patterning and coding. J. Mater. Chem. C 1, 4925-4932 (2013).

5. Sahu, S., Behera, B., Maiti, T. K. \& Mohapatra, S. Simple one-step synthesis of highly luminescent carbon dots from orange juice: application as excellent bio-imaging agents. Chem. Commun. 48, 8835-8837 (2012).

6. Zhang, Z., Sun, W. \& Wu, P. Highly photoluminescent carbon dots derived from egg white: facile and green synthesis, photoluminescence properties, and multiple applications. ACS Sustain. Chem. Eng. 3, 1412-1418 (2015).

7. Hua, X. W., Bao, Y. W., Wang, H. Y., Chen, Z. \& Wu, F. G. Bacteria-derived fluorescent carbon dots for microbial live/dead differentiation. Nanoscale 9, 2150-2161 (2017).

8. Baker, S. N. \& Baker, G. A. Luminescent carbon nanodots: emergent nanolights. Angew. Chem. Int. Ed. 49, 6726-6744 (2010). 
9. Kelarakis, A. From highly graphitic to amorphous carbon dots: a critical review. MRS Energy Sustain. 1, E2. https://doi.org/10. 1557/mre.2014.7 (2014).

10. Li, H., Kang, Z., Liu, Y. \& Lee, S. T. Carbon nanodots: synthesis, properties and applications. J. Mater. Chem. 22, 24230-24253 (2012).

11. Lim, S. Y., Shen, W. \& Gao, Z. Carbon quantum dots and their applications. Chem. Soc. Rev. 44, 362-381 (2015).

12. Himaja, A. L., Selvam, K. P., Bojja, S. \& Singh, S. P. Synthesis of carbon dots from kitchen waste: conversion of waste to value added product. J. Fluoresc. 24, 1767-1773 (2014).

13. Li, W. et al. Simple and green synthesis of nitrogen-doped photoluminescent carbonaceous nanospheres for bioimaging. Angew. Chem. Int. Ed. 52, 8151-8155 (2013).

14. Yang, S. T. et al. Carbon dots as nontoxic and high-performance fluorescence imaging agents. J. Phys. Chem. C 113, 18110-18114 (2009).

15. Han, M. et al. Recent progress on the photocatalysis of carbon dots: Classification, mechanism and applications. NanoToday 19, 201-218 (2018).

16. Essner, J. B. \& Baker, G. B. The emerging roles of carbon dots in solar photovoltaics: a critical review. Environ. Sci. Nano. 4, 1216-1263 (2017).

17. Xu, J. et al. Carbon dot-based white and yellow electroluminescent light emitting diodes with a record-breaking brightness. Nanoscale 10, 1121-1122 (2018).

18. Molai, M. J. A review on nanostructured carbon quantum dots and their applications in biotechnology, sensors, and chemiluminescence. Talanta 196, 456-478 (2019).

19. Luo, P. G. et al. Carbon "quantum" dots for optical bioimaging. J. Mater. Chem. B 1, 2116-2127 (2013).

20. Kong, T., Hao, L., Wei, Y., Cai, X. \& Zhu, B. Doxorubicin conjugated carbon dots as a drug delivery system for human breast cancer therapy. Cell Prolif. 51, e12488. https://doi.org/10.1111/cpr.12488 (2018).

21. Wang, W. et al. Water-induced poly(vinyl alcohol)/carbon quantum dot nanocomposites with tunable shape recovery performance and fluorescence. J. Mater. Chem. B 6, 7444-7450 (2018).

22. Fernandes, D., Heslop, K. A., Kelarakis, A., Krysmann, M. J. \& Estevez, L. In situ generation of carbon dots within a polymer matrix. Polymer 188, 122159. https://doi.org/10.1016/j.polymer.2020.122159(2020).

23. Fernandes, D., Krysmann, M. J. \& Kelarakis, A. Carbon dot based nanopowders and their application for fingerprint recovery. Chem. Commun. 51, 4902-4905 (2015).

24. Shih, C., Chen, P., Lin, G., Wang, C. \& Chang, H. Optical and electrochemical applications of silicon-carbon dots/silicon dioxide nanocomposites. ACS Nano 9, 312-319 (2015).

25. Zhu, S. et al. Highly photoluminescent carbon dots for multicolor patterning, sensors, and bioimaging. Angew. Chem. Int. Ed. 52, 3953-3957 (2013).

26. Wang, G. et al. Facile and highly effective synthesis of controllable lattice sulfur-doped graphene quantum dots via hydrothermal treatment of durian. ACS Appl. Mater. Interfaces 10, 5750-5759 (2018).

27. Tian, Y. et al. Dramatic photoluminescence quenching in carbon dots induced by cyclic voltammetry. Chem. Commun. 54, 90679070 (2018).

28. Krysmann, M. J., Kelarakis, A., Dallas, P. \& Giannelis, E. P. Formation mechanism of carbogenic nanoparticles with dual photoluminescence emission. J. Am. Chem. Soc. 134, 747-750 (2012).

29. Wang, W. et al. Shedding light on the effective fluorophore structure of high fluorescence quantum yield carbon nanodots. RSC Adv. 7, 24771-24780 (2017).

30. Kasprzyk, W. et al. Luminescence phenomena of carbon dots derived from citric acid and urea-a molecular insight. Nanoscale 10, 13889-13894 (2018).

31. Wang, H. et al. Fluorescently tuned nitrogen-doped carbon dots from carbon source with different content of carboxyl groups. APL Mater. 3, 086102. https://doi.org/10.1063/1.4928028 (2019).

32. $\mathrm{Xu}, \mathrm{M}$. et al. A green heterogeneous synthesis of $\mathrm{N}$-doped carbon dots and their photoluminescence applications in solid and aqueous states. Nanoscale 6, 10307-10315 (2014).

33. Zheng, C., An, X. \& Gong, J. Novel pH sensitive $\mathrm{N}$-doped carbon dots with both long fluorescence lifetime and high quantum yield. RSC Adv. 5, 32319-32322 (2015).

34. Wu, Z. L. et al. A general quantitative $\mathrm{pH}$ sensor developed with dicyandiamide $\mathrm{N}$-doped high quantum yield graphene quantum dots. Nanoscale 6, 3868-3874 (2014).

35. Tian, Z. et al. Full-color inorganic carbon dot phosphors for white-light-emitting diodes. Adv. Optical Mater. 5, 1700416. https:// doi.org/10.1002/adom.201700416 (2017).

36. Gu, S. et al. Fluorescence of functionalized graphene quantum dots prepared from infrared-assisted pyrolysis of citric acid and urea. J. Lumin. 217, 116774. https://doi.org/10.1016/j.jlumin.2019.116774 (2020).

37. Gu, S. et al. Microwave growth and tunable photoluminescence of nitrogen-doped graphene and carbon nitride quantum dots. J. Mater. Chem. C 7, 5468-5476 (2019).

38. Ma, Y. et al. Doping effect and fluorescence quenching mechanism of $\mathrm{N}$-doped graphene quantum dots in the detection of dopamine. Talanta 196, 563-571 (2019).

39. Sharma, A. et al. Interaction of carbon dots with endothelial cells: implications for biomedical applications. ACS Appl. Nano Mater. 2, 5483-5491 (2019).

40. Permatasari, F. A., Fukazawa, H., Ogi, T., Iskandar, F. \& Okuyama, K. Design of pyrrolic-N-rich carbon dots with absorption in the first near-infrared window for photothermal therapy. ACS Appl. Nano Mater. 1, 2368-2375 (2018).

41. Xue, Z., Gao, H. \& Li, X. A Green and lower-temperature synthesis of two-color fluorescent nitrogen doped graphene quantum dots. Dyes Pigm. 156, 379-385 (2018).

42. Qu, D. et al. Highly luminescent S, N co-doped graphene quantum dots with broad visible absorption bands for visible light photocatalysts. Nanoscale 5, 12272-12277 (2013).

43. Qu, S. et al. Toward efficient orange emissive carbon nanodots through conjugated $\mathrm{sp}^{2}$-domain controlling and surface charges engineering. Adv. Mater. 28, 3516-3521 (2016).

44. Ogi, T. et al. Kinetics of nitrogen-doped carbon dot formation via hydrothermal synthesis. New J. Chem. 40, 5555-5561 (2016).

45. Ogi, T. et al. Transient nature of graphene quantum dot formation via a hydrothermal reaction. RSC Adv. 4, 55709-55715 (2014).

46. Qu, D. et al. Formation mechanism and optimization of highly luminescent N-doped graphene quantum dots. Sci. Rep. 4, 5294. https://doi.org/10.1038/srep05294 (2014).

47. Dong, Y. et al. Blue luminescent graphene quantum dots and graphene oxide prepared by tuning the carbonization degree of citric acid. Carbon 50, 4738-4743 (2012).

48. Wang, T. et al. Carbon dots with molecular fluorescence and their application as a "turn-off" fluorescent probe for ferricyanide detection. Sci. Rep. 9, 10723. https://doi.org/10.1038/s41598-019-47168-7 (2019).

49. Miao, X. et al. Synthesis of carbon dots with multiple color emission by controlled graphitization and surface functionalization. Adv. Mater. 30, 1704740. https://doi.org/10.1002/adma.201704740 (2017).

50. Santiago, S. R. M. et al. Effect of nitrogen doping on the photoluminescence intensity of graphene quantum dots. Opt. Lett. 42, 3642-3645 (2017). 
51. Simões, E. F. C., Leitão, J. M. M. \& Esteves da Silva, J. C. G. Carbon dots prepared from citric acid and urea as fluorescent probes for hypochlorite and peroxynitrite. Microchim Acta 183, 1769-1777 (2016).

52. Cao, X. et al. A facile microwave-assisted fabrication of fluorescent carbon nitride quantum dots and their application in the detection of mercury ions. Spectrochim. Acta Part A Mol. Biomol. Spectrosc. 151, 875-880 (2015).

53. Bao, X. et al. In vivo theranostics with near-infraredemitting carbon dots-highly efficient photothermal therapy based on passive targeting after intravenous administration. Light Sci. Appl. 7, 91. https://doi.org/10.1038/s41377-018-0090-1 (2018).

54. Wang, J. et al. Simply synthesized nitrogen-doped graphene quantum dot (NGQD)-modified electrode for the ultrasensitive photoelectrochemical detection of dopamine. Nanophotonics 9, 3831-3839 (2019).

55. Liu, W. et al. Highly crystalline carbon dots from fresh tomato: UV emission and quantum confinement. Nanotechnology 28, 485705. https://doi.org/10.1088/1361-6528/aa900b (2017).

56. Yang, C. et al. Biodegradable polymer-coated multifunctional graphene quantum dots for light-triggered synergetic therapy of pancreatic cancer. ACS Appl. Mater. Interfaces 11, 2768-2781 (2019).

57. Wang, W., Damm, C., Walter, J., Nacken, T. J. \& Peukert, W. Photobleaching and stabilization of carbon nanodots produced by solvothermal synthesis. Phys. Chem. Chem. Phys. 18, 466-475 (2016).

58. Qu, S., Wang, X., Lu, Q., Liu, X. \& Wang, L. A biocompatible fluorescent ink based on water-soluble luminescent carbon nanodots. Angew. Chem. Int. Ed. 51, 12215-12218 (2012).

59. Reckmeier, C. J. et al. Aggregated molecular fluorophores in the ammonothermal synthesis of carbon dots. Chem. Mater. 29, 10352-10361 (2017).

60. Ehrat, F. et al. Tracking the source of carbon dot photoluminescence: aromatic domains versus molecular fluorophores. Nano Lett 17, 7710-7716 (2017).

61. Devi, J. S. A. et al. Understanding the citric acid-urea co-directed microwave assisted synthesis and ferric ion modulation of fluorescent nitrogen doped carbon dots: a turn on assay for ascorbic acid. Chem. Select 4, 816-824 (2019).

62. Schaber, P. M. et al. Thermal decomposition (pyrolysis) of urea in an open reaction vessel. Thermochim. Acta 424, 131-142 (2004).

63. Niu, X., Li, Y., Shu, H. \& Wang, J. Revealing the underlying absorption and emission mechanism of nitrogen doping graphene quantum dots. Nanoscale 8, 19376-19382 (2016).

64. Zholobak, N. M. et al. Facile fabrication of luminescent organic dots by thermolysis of citric acid in urea melt, and their use for cell staining and polyelectrolyte microcapsule labelling. Beilstein J. Nanotechnol. 7, 1905-1917 (2016).

65. Sciortino, A. et al. $\beta-\mathrm{C}_{3} \mathrm{~N}_{4}$ nanocrystals: carbon dots with extraordinary morphological structural and optical homogeneity. Chem. Mater. 30, 1695-1700 (2018).

66. Zhu, S. et al. The photoluminescence mechanism in carbon dots (graphene quantum dots, carbon nanodots, and polymer dots): current state and future perspective. Nano Res. 8, 355-381 (2015).

67. Kelarakis, A. Graphene quantum dots: In the crossroad of graphene, quantum dots and carbogenic nanoparticles. Curr. Opin. Colloid Interface Sci. 20, 354-361 (2015).

68. Jin, L., Wang, Y., Yan, F., Zhang, J. \& Zhong, F. The synthesis and application of nitrogen-doped graphene quantum dots on brilliant blue detection. J. Nanomater. 2019, 1471728. https://doi.org/10.1155/2019/1471728 (2019).

69. Schneider, J. et al. Molecular fluorescence in citric acid-based carbon dots. J. Phys. Chem. C 121, 2014-2022 (2017).

70. Xiong, Y., Schneider, J., Ushakova, E. V. \& Rogach, A. L. Influence of molecular fluorophores on the research field of chemically synthesized carbon dots. Nano Today 23, 124-139 (2018).

71. Fernandes, D., Krysmann, M. J. \& Kelarakis, A. Carbogenically coated silica nanoparticles and their forensic applications. Chem. Commun. 52, 8294-8296 (2016).

72. Peng, D., Liu, X., Huang, M., Wang, D. \& Liu, R. A novel monodisperse SiO $\mathrm{O}_{2} @ \mathrm{C}$-dot for the rapid and facile identification of latent fingermarks using self-quenching resistant solid-state fluorescence. Dalton Trans. 47, 5823-5830 (2018).

73. Jiang, B. P. et al. White-emitting carbon dots with long alkyl-chain structure: Effective inhibition of aggregation caused quenching effect for label-free imaging of latent fingerprint. Carbon 128, 12-20 (2017).

74. Zhang, Y. et al. Solid-state fluorescent carbon dots with aggregation-induced yellow emission for white light-emitting diodes with high luminous efficiencies. ACS Appl. Mater. Interfaces 11, 24395-24403 (2019).

75. Yoo, H. J., Kwak, B. E. \& Kim, D. H. The self-quenching origin of carbon dots and the guideline for its solid-state luminescence. J. Phys. Chem. 123, 27124-27131 (2019).

76. Hossan, A. S. M., Abu-Melha, H. M. A., Al-Omar, M. A. \& Amr, A. E. G. E. Synthesis and antimicrobial activity of some new pyrimidinone and oxazinone derivatives fused with thiophene rings using 2-chloro-6-ethoxy-4-acetylpyridine as starting material. Molecules 17, 13642-13655 (2012)

77. Westhuyzen, R. et al. Pyrrolo[3,4-c]pyridine-1,3(2H)-diones: a novel antimycobacterial class targeting mycobacterial respiration. J. Med. Chem. 58, 9371-9381 (2015).

78. Burel, C., Kala, A. \& Purevdorj-Gage, L. Impact of $\mathrm{pH}$ on citric acid antimicrobial activity against Gram-negative bacteria. Lett. Appl. Microbiol. https://doi.org/10.1111/lam.13420 (2021).

79. Landry, J. J. M. et al. The genomic and transcriptomic landscape of a HeLa cell line. G3 Bethesda 3, 1213-1224 (2013).

80. Li, D. et al. Supra-(carbon nanodots) with a strong visible to near-infrared absorption band and efficient photothermal conversion. Light Sci. Appl. 5, 1-8 (2016).

81. Yu, T. et al. A rapid microwave synthesis of green-emissive carbon dots with solid-state fluorescence and $\mathrm{pH}$-sensitive properties. R. Soc. Open Sci. 5, 180245-180256 (2018).

82. Gibbons, E. N. et al. Layer by layer antimicrobial coatings based on nafion, lysozyme, and chitosan. Nanomaterials $\mathbf{9 ,} 1563$ (2019).

\section{Acknowledgements}

Financial support from UCLan Research Centre for Smart Materials is gratefully acknowledged. Use of HRTEM facilities at Sabancı University Nanotechnology Research and Application Center (SUNUM) is acknowledged. Also, use of STEM facilities at Ondokuz Mayis University Black Sea Advanced Technology Research and Application Center (KITAM) is acknowledged.

\section{Author contributions}

The work was conceived by A.K, supervised by A.K., M.J.K., C.M. and S.G.Y., experiments and data analysis were carried out by J.D.S., A.M., D.F., E.N.G., J.M., E.B., Writing of the manuscript was done by A.K. and J.D.S. All authors reviewed the manuscript.

\section{Competing interests}

The authors declare no competing interests. 


\section{Additional information}

Supplementary Information The online version contains supplementary material available at https://doi.org/ 10.1038/s41598-021-89984-w.

Correspondence and requests for materials should be addressed to A.K.

Reprints and permissions information is available at www.nature.com/reprints.

Publisher's note Springer Nature remains neutral with regard to jurisdictional claims in published maps and institutional affiliations.

(c) (1) Open Access This article is licensed under a Creative Commons Attribution 4.0 International cc) License, which permits use, sharing, adaptation, distribution and reproduction in any medium or format, as long as you give appropriate credit to the original author(s) and the source, provide a link to the Creative Commons licence, and indicate if changes were made. The images or other third party material in this article are included in the article's Creative Commons licence, unless indicated otherwise in a credit line to the material. If material is not included in the article's Creative Commons licence and your intended use is not permitted by statutory regulation or exceeds the permitted use, you will need to obtain permission directly from the copyright holder. To view a copy of this licence, visit http://creativecommons.org/licenses/by/4.0/.

(C) The Author(s) 2021 